\title{
Threats to Green Gum Arabic Production in Sudan
}

\author{
Abu Bakr El Siddig Ahmed Eltohami* \\ Omdurman Ahlia University, Associate Professor of Environmental Management and Impact Assessment, Sudan
}

Received: March 27, 2018; Published: April 11, 2018

*Corresponding author: Abu Bakr El Siddig Ahmed Eltohami, Faculty of Environmental Sciences, Omdurman Ahlia University, Associate Professor of Environmental Management and Impact Assessment Environmental Auditor, Reviewer for number of Journals, Sudan, Email: abubakreltohami07@gmail.com

\begin{abstract}
The rural population of Sudan, and much of its urban population, depends on rests. Trees are the main source of energy and provide timber for roofing and building. The extensive benefits derived from forests include grazing, hunting, shade, forest foods in the form of tree leaves, wild fruits, nuts, tubers and herbs, tree bark for medicinal purposes, and non-wood products such as honey and gum Arabic. In addition, the commercial lumber industry is a small but growing source of employment. This paper aims at identifying the threats facing sustainable gum Arabic production. Gum Arabic production and marketing in Sudan is witnessing many constraints which can be summarized as follow: expansion of mechanized rain-fed agricultural schemes on natural forests, commercial fuel wood and charcoal making activities (Figure 1), late tapping, infestation of pests such as desert locusts and Queasier quealia Ethiopica birds, nomadic pastoralists, Furthermore pricing policies of Gum Arabic Company and limited financial budgets allocated for buying the gum from the, the importers of gum.
\end{abstract}

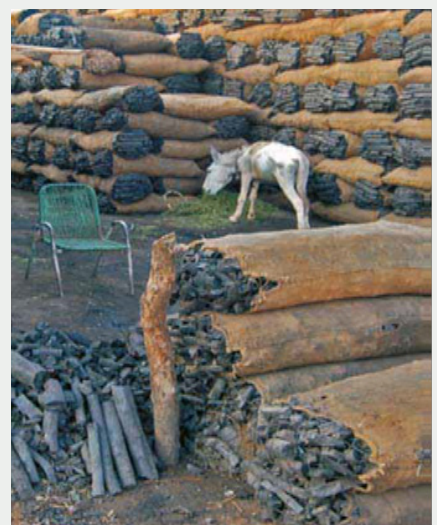

Figure 1: A charcoal market in Khartoum.

Arabic indirectly encourage the farmers to plant Taleh (Acaciya seyal) by claiming Tale gum rather than gum from Hashed (Acacia Senegal), adverse climatic conditions. However, Sudanese gum Arabic in the international markets faces a lot of constraints viz. western and eastern African countries became more aware of the importance of this commodity, smuggling of Sudanese gum Arabic. They impose no taxes or fees on gum Arabic commodity, very limited domestic consumption, presence of synthetic compounds substituting it in foodstuff $\backslash$ manufacturing industries, limited international demand. Sustainable gum Arabic production can be achieved through tapping at the optimum time, scheduling reforestation programmes and revising gum Arabic pricing policies and allotting sufficient fund encourage the gum Arabic producers.

Keywords: Green production; Sustainable; Gum Arabic; Tapping; Mechanized rain fed agricultural schemes

\section{Introduction}

A wide range of forests and related vegetation types is found in Sudan due to regional variations in soil and rainfall. The most important types are listed as follows: desert and semi-desert trees and shrubs; reverie forests; low rainfall woodland savannah; high rainfall woodland savannah; montane and gallery forests; tropical forests [1]. Most trees in Sudan grow in open to semi-closed woodlands with numerous under-storeys of grasses and shrubs.
Fully closed forests are only found in a few of the most humid areas in the south. This complicates attempts to quantify the extent of forests and deforestation in the drier regions, as there is rarely a clear deforestation or ecosystem boundary, but rather a gradual thinning out of trees over a large areas Ibid. According to FAO, the forestry sector contributes as much as 13 percent to the gross domestic product of Sudan. This valuable resource is threatened, 
however, by deforestation driven principally by energy needs and u clearance.

Moreover, the unbalanced distribution of forests in Sudan - most of the remaining forests are found in the south, while the demand for forest products is highest in the north - presents a potential threat for north south peace, but also a significant opportunity for sustainable north-south trade development. The objectives of this paper are to identify the constraints of sustainable gum Arabic production and marketing. Acacia senegal (L.) Wild. is a tree (or shrub) of 2-6 m, occasionally up to $8 \mathrm{~m}$ in height, with umbrella-shaped crown. It is very branched with many upright twigs [1]. A. Senegal, locally called hashab tree, grows in a range of annual rainfall between 100-800 mm (mainly between 300$400 \mathrm{~mm}$ ). It is very drought resistant and tolerates dry periods of 8-11 months. The species prefers sandy soils, but grows also on slightly loamy sands [1]. In the respective parts of Sudan A. Senegal dominates the vegetation cover, and exists in the wild as well as on cultivated land - mainly on sandy hills, but also on cotton soil Ibid.

With regard to ecological and socio-economic relevance, $A$. Senegal is a multifunctional tree in Sudan producing gum Arabic, particularly in the western part of the country. Acacia senegal has a remarkable adaptability to drought and frost. It contributes substantially to Sudan exports and, thus, to the revenues of the farming communities of gum belt. Gum production is a pillar of family economy and considered as an income-generating source that requires only a low input of work after the rainy season. Besides gum Arabic production, the tree species has been used for desertification control, reestablishment of a vegetation cover in degraded areas, sand dune fixation and wind erosion control. It plays an important role in soil stabilization through a widely extended lateral root system and possibly contributes to soil improvement through nitrogen fixation as well as mineral enrichment from leaf litter [2].

\section{Objective}

To identify causes and effects of non-sustainable gum Arabic Production

\section{Materials and Methods}

\section{Background to Research Problem}

Desert vegetation in the northern states (Northern, Northern Darfur, Northern Kordofan, Kassala and Red Sea) is limited to xerophytes (drought resistant) shrubs, such as Acacia ehrenbergiana,Capparis decidua, Favonian critical and Leptodenia pyrotechnical. Scrub formations occur in the semi-desert zone (the northern half of Cordovan and Blue Nile states, all of Khartoum state, most of Red Sea state, and some parts of Darfur). The vegetation is a varying mixture of grasses and herbs with widely scattered shrubs. Forest resources in the desert and semi-desert northern states are extremely limited and are continuously declining. Reverie forests are a critical resource for the northern states. They occupy the lands that are flooded when rivers rise in the latter part of the wet season.

Acacia militia - the dominant species - is found as pure dense stands over large areas from the Egyptian border in the north to as far south as Javelin on the White Nile, and Rosaries on the Blue Nile (Figure 2). The species also occurs along the Dander and Rah Ad Rivers. In less frequently flooded basins along the Atbara River and in some inland sites, Acacia militia is replaced by Hyphaene thebaica (Dom palm) forests [3]. The low rainfall woodland savannah region lies in the centre and south of the country, with the exclusion of the flood region. Rainfall is confined to a few months of the year (March or April to July), and is followed by a long hot dry season. The vegetation is composed of mixed grass types with bushes and trees, but species distribution within the low rainfall savannah zone varies with rainfall and soil type. Sandy soils dominate in the west and central regions, and clay soils are prevalent in the east and south. In the drier parts, trees are nearly all thorny and low in stature, with a predominance of species of acacia.

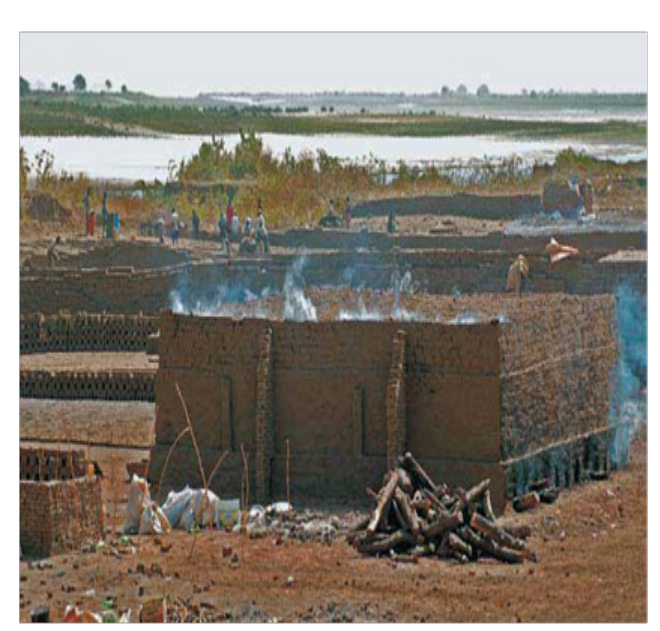

Figure 2: Brick kilns on the banks of the Blue Nile, in El Gezira state. The brick-making industry is a major market for fuel wood.

Broadleaved deciduous trees become prevalent in the wetter parts, but there is not as great a variety of species as in the high rainfall woodland savannah, and thorn trees are usually present. The gum Arabic belt lies within this zone. The belt occupies an area of $520,000 \mathrm{~km} 2$ between the latitudes of $10^{\circ}$ and $14^{\circ} \mathrm{N}$, accounting for one-fifth of the total area of the country. Its importance is reflected in the fact that it accommodates approximately one-fifth of the population of Sudan and two-thirds of its livestock, and that it acts as a natural barrier to protect more than 40 percent of the total area of Sudan from desert encroachment. The density and variety of tree cover increases further south. Mountains in Sudan are characterized by higher rainfall, resulting in different and more robust woodlands than in the surrounding areas. The Jebel Mara plateau in Darfur is the most important ecosystem of this type in the drier parts of Sudan [4]. Plantations were first established in Sudan by the Anglo-Egyptian administration.

This process was continued by the government forestry administration, and by the mid-1970s, plantations totalled some 16,000 additional hectares of hardwoods and 500 to 600 hectares of softwoods. Nowadays plantations are comprised of reverie Acacia nilotica forests, Acacia senegal plantations in abandoned 
mechanized farms, inside forest reserves, in private gum orchards, and in isolated shelter belts planted in Northern Cordovan and other central states, pine and eucalyptus plantations in the Jebel Mara region in Darfur, and eucalyptus in the irrigated agricultural areas. There are several underlying causes of deforestation in Sudan; these are cumulative in nature and vary considerably from region to region: fuel wood and charcoal extraction; mechanized agriculture; traditional rain-fed and shifting agriculture; drought and climate change; over browsing and fires; direct conflict impacts; commercial lumber and export industry (not a major factor); and traditional construction [3].

\section{Methods}

Data collection through using three methods:

a. A-secondary data by critical reviewing the available literature

b. B- Field survey conducted by the author by interviewing of the gum Arabic producers using questionnaires and

c. C- open interviewing the local officials and key informants

\section{Results and Discussion}

\section{Causes of Non-Sustainable Gum Arabic Production and Marketing}

After post field survey the following constraints, facing gum Arabic production and marketing, had been identified:

a. Expansion of mechanized farming schemes at the expense of natural forests,

b. wood and charcoal production

c. Fierce attack of natural forests by nomadic pastoralists

d. Pricing policy of Gum Arabic company

e. The negative relation between gum from hashab and gum from Talih. The importing countries encourage the producers to plant Acacia melifera) Kitir instead of Acacia senegal by claiming Talca gum rather than gum Arabic

f. Late announcement gum Arabic prices by the company

g. International conspiracy against Sudan

h. Adverse climatic conditions

i. Expansion of mechanized farming schemes at the expense of natural forests for instance Dali schemes replaced 205,000 feedings of natural forests.

This reduction in areas previously occupied by natural forests was directly reflected on gum Arabic production. This expansion was attributed to Sudan government policy towards food security. Clearance of forests for cultivation since at late fifties and early sixties times the cost was rather low as well as that productivity was high. At present the area under this sector has reached 662,000 sedans which were occupied in the past of natural forests [5].

a. Large scale commercial fuel wood and charcoal production. Despite the fact that local forestry authority gives annual permission for fuel wood and charcoal producers yet, some traders are practicing illegal removal of forests. Not only that they exceed the areas devoted to them by the authority.

b. For building houses (Red Brick Industry)

\section{Factors Affecting Acacia senegal Growth and Health Conditions}

Many parameters affect growth and health condition of $A$. Senegal. These are physical factors (climate, soils, water balance, and topography), biological factors (diseases and pests, especially insect and rodent attacks, browsing by livestock and game), traditional constraints (human land use systems), socioeconomic parameters (working opportunities, migration, revenues), and political features including land tenure, rural development policies, infrastructure and transport, organization of local trade and export, pricing and taxation, local industries as well as marketing, (i.e. the whole range of traditional and moderns structures required to collect, store, transport, grade and sell gum Arabic at home and abroad; market forecasts [2].

\section{Threats to Acacia senegal}

As it as mentioned before Vast expansion of Mechanized rain fed schemes has resulted in the removal of natural $A$. Senegal forests leading to drastic drop of gum Arabic production mainly in clay soils of central Sudan [6]. [1]. mentioned that the importance of $A$. Senegal conflicts with its susceptibility to different threats. Fires kill off seedlings and damage the trees. A good deal of damage is caused through cutting off large branches. The tree is e.g. vulnerable to the attack of fungi, termites, locusts (Anacridium melanorhodon), grasshoppers, long horned beetles and borers, as well as goats and [7]. Frequently pests cause defoliation and thus, decrease the photosynthetic capability of Acacia senegal and in turn the quality of stored carbohydrates connected with a reduction of gum yield. Pest outbreaks are often difficult to predict and costly to control and may cause considerable damage, compromise national economies, local livelihoods and food security, and result in trade restrictions on forest products.

\section{Anthropogenic Constraints to Gum Arabic Production}

[2]. mentioned that Gum Arabic production processes experience many constraints, which have reduced production in terms of quantity and quality resulting in price inconvenience to producers and other stakeholders at upper stream level. Some technical and institutional constraints hindering gum Arabic production potentiality in area were also encountered during the field survey. These are conflicts over resources, insufficient information on the gum Arabic resource base with national forest inventory (NIF) and national governmental strategies and plans.

The gum Arabic production has been constrained with several problems such as lack and poor management of village nurseries, traditional way of gum production (using of axe, collection tools and mal-cultural practices, low tapping intensity per trees and per area, lack of large scale Production). In addition to, improper postharvest techniques i.e. drying, use of plastic sacks and bags [2]. It is worth mentioning that some production sites are in remote areas 
compared to markets, with poor infrastructures and services These are: drinking water, storage facilities, means of transportation, extension, official finance, education and health units, limited sources of income, insufficient and unskilled labor force, traditional gold mining, rural-urban migration, lack of value addition activities fire hazards, tree locust \& other pests

\section{Pricing policies of Gum Arabic Company}

The local traders are essential elements of the local gum Arabic markets because they have great experience and influence in buying, cleaning and assorting the gum higher prices. These prices experience continuous increase every [8].

\section{Constraints of Sudanese gum Arabic in the international markets}

According to [8]. these constraints could be summed up in the followings: Western and eastern Africa countries lie in the gum Arabic belt (viz. Nigeria, Chad, Mali, Niger, Mauritania, Senegal and Ethiopia), became aware of the importance of this commodity. As result they increased the forested with Has hab and look for support from consumers' countries such as France with Chad. USAID conducted seminars and workshops in these countries for improving and increasing their gum Arabic production. The above mentioned competing countries produce about 10,000 tons/ annum. No taxes and fees taken or imposed on Gum Arabic commodity in these competing countries in contrary to Sudan where heavy taxes and.

\section{Late announcement of Gum Arabic prices}

It is very crucial to mention that the competing countries are used to announce their prices after Sudan. This delay enables them to reduce their prices to the extent that they can sell their whole production at rather lower prices.

\section{Smuggling of Sudanese gum to The Neighbouring Countries}

It occurs because Gum Arabic Company is monopolizing the market and dominating it [9].

\section{Limited Local Consumption of gum and Demand in the International Markets:}

There is a very limited local consumption of gum (since it ranges between 25,000 - 30,000 tons per year, the average exported Sudanese gum Arabic is about 20,000 annually). Moreover, there are limited trails for the processing of raw gum before exporting it to the international markets. This is in turning implied the importance of efficient planning and flexible marketing policies so that added values can be obtained.

\section{Availability of Synthetic Materials}

On the basis of the above mentioned factors Sudanese gum Arabic production and exports are experiencing non-sustainability.

\section{The Negative Role Played by Government}

Although the cost of production of gum Arabic is negligible compared to other agricultural crops, yet the government puts heavy burden on rit. tremendous changes in the international markets since the importing countries $s$ themselves to other substitutes which have lower prices e. g. USD 1400 per ton compared to prices announced by Sudan (USD 4000 per ton). Moreover, the other negative international market dropped even at lower prices. Despite of this, the government had continued or to impose higher customary rates on this commodity which reached in year 1998 more than 15 billion SDG taken from gum Arabic company alone. Added this, so many taxes under different names e.g. zaka, ushor and gebana. The net result of these pricing is not sustainable return from this commodity [10].

\section{The International Conspiracy Against Sudanese Gum Arabic}

There are certain specifications or prerequisites for any commodity to be sold in the international market. With regard to gum Arabic certain definition had been prepared by a group of experts from the international consultants of FAO and WHO in 1978. This definition had been revised during years 1982, 1986, without any change in specification (personal communication of the author). The definition of gum Arabic during the period from 1978 - 1986 was that "gum Arabic is the dried exudation obtained from stems and branches of /Acacia senegal (L) wildnew or closcely related species of (Acacia family leguminase). It consists mainly of high molecular-weight polysaccharides and their calcium, magnesium and potassium salts, which on hydrolysis yield arabinose, galaxies, ramose and glocuronic acid. The article of commerce may be further specified to the viscosity since in 1990 a change in definition took place adding" or the related species of Acacia" instead "closely relate species.

Another two new properties: rotational viscosity (260-340) and nitrogen (from 0.271 to 0.391 ) were put under the title identified test". These two properties did not coincide with all gum but they are confined to gum from Hashab. Not all Acacia gum other than has hab can have the same effect of rotational viscosity and nitrogen content. This makes the of addition of words related to other species is re redundant [8]. In 1992 an experts Committee of Food Additive (JECFA) announced but without mentioning the two specifications. As a result of this definition a technical Sudanese Committee said that the definition should be read as follows: "Gum Arabic is the a Acacia senegal(L) Widely (family leguminosae". It consists mainly of salts and arabinose. Sudanese mission participated in the meeting launched in Dan Hague (The Netherlands) on March 1998 and Sudan opposed the proposal of changing the definition which stated that: "Gum Arabic is the dried exudation obtained from stems and branches of Acacia senegal (L) wildnew or closcely related species of (Acacia family leguminase)".Acacia seyal (Talih) is the closely related species. Gum Arabic from Acacia seyal (Talih) is sometimes referred to as Talha. The rotational viscosity was added as follows:

a. Gum from Acacia senegal: water solutions are levorotatory.

b. Gum from Acacia seyal: water solutions are dexorotatory without any specification of rotational viscosity is due to big difference 
This ambiguous definition leaves the gate open for objection the ne of other Acacias gum from other genera in the future. Due to the objection of Sudan, supported e other countries, this standardization returned to FAO food expert's committee definition. The existing standardization is that of 1990.

On the other hand the conspiracy against Sudan continued through increasing the export of gum Talh at the expense of gum from has hab.

According to Dali Gum Arabic production Union, these constraints

a. Drought periods lead to felling of trees and reduction in the producing areas

b. Gum Arabic marketing policies

c. Attack of Has hab trees by nomads

\section{Conclusions and Recommendations}

\section{Conclusion}

The non sustainability of gum Arabic production and marketing was to be caused by:

a. late tapping

b. insufficient rains

c. gum Arabic marketing policy

d. gum smuggling to neighboring countries

e. international conspiracy against Sudan

f. encroachment of mechanized farming schemes on vast areas of natural Hashab forests

\section{Recommendations}

To attain sustainable gum Arabic production and marketing the following recommendations can be drawn:
a. tapping at the optimum time
b. scheduling reforestation programmes
c. control of pests and diseases
d. revising of gum Arabic pricing policy
e. Abolition of heavy taxes
f. Smuggling combating campaign

\section{References}

1. Eisa MA, Roth M, Sama G (2008) Acacia senegal (Gum Arabic Tree): Present Role and Need for Future Conservation/ Sudan.

2. Adam HE, Eltahir ME S, Elhaja ME Ibrahim AH, Abdelkareem OE Hammad, et al. (2017) Management of Gum Arabic Production Potentialities in the Gum Belt in Kordofan, Sudan,International. Journal of Environmental Planning and Management 3(1): 1-9.

3. UNEP (2007) Sudan Post Conflict: Environmental assessment, Kenya.

4. El Khlalifa M, Nour HO (Eds.). (1992) United Nations conference on Environment and Development, Brbazil.

5. El Tohami, AE A (2013) Constraints of Sustainable Livestock Production in Sudan, Sustainable Development Conference, Bangkok, Thailand.

6. El tohami AE A (1993) The impact of Hashab (Acacia Senegal) reforestation on Sustainable Development, Case study of Dali Mechanized schemes of Dali, M.Sc. University of Khartoum, Sudan.

7. El Tohami AE A (2013) Threats to food security in Sudan, FSDL Conference, Doha, Qatar

8. El tohami AE A (1999) Towards an environmentally sustainable Development in the Mechanized rain fed agriculture of Sudan with special emphasis on socioeconomic aspects, a case study of Dali Mechanized schemes, Ph.D. Thesis, University of Khartoum, Sudan.

9. El Tohami AE A (2014) Indigenuous cultural practices: A path for Green Food Production in Sudan, first congress of conservation Agriculture, Zambia.

10. El Tohami AE A (2006) Constraints of sustainable food production in the Dali Mechanized Schemes, Development and Environment in Sudan conference, Sudan.

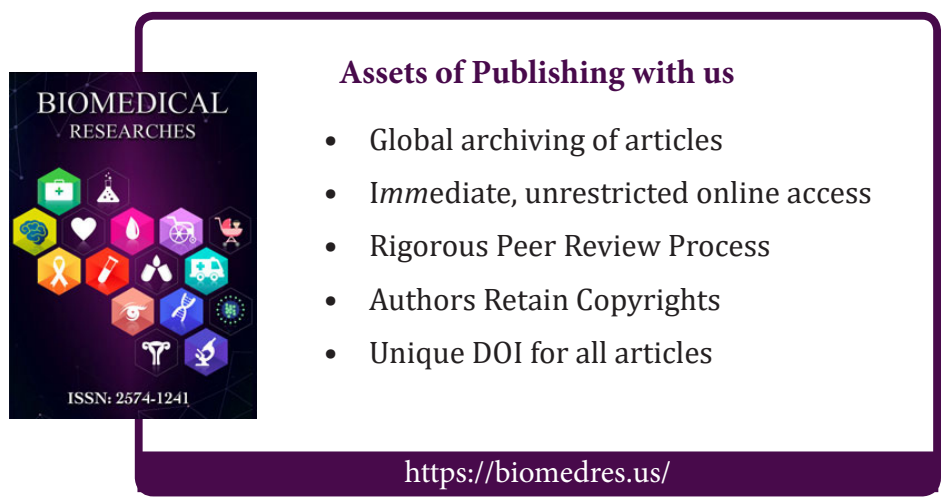

